\title{
Numerical simulation of buckling behavior of the buried steel pipeline under reverse fault displacement
}

\author{
J. Zhang, Z. Liang, C. J. Han, and H. Zhang \\ School of Mechatronic Engineering, Southwest Petroleum University, Chengdu, 610500, China \\ Correspondence to: J. Zhang (longmenshao@163.com)
}

Received: 22 October 2014 - Revised: 11 September 2015 - Accepted: 16 September 2015 - Published: 22 September 2015

Abstract. Reverse fault movement is one of the threats for the structural integrity of buried oil-gas pipelines caused by earthquakes. Buckling behavior of the buried pipeline was investigated by finite element method. Effects of fault displacement, internal pressure, diameter-thick ratio, buried depth and friction coefficient on buckling behavior of the buried steel pipeline were discussed. The results show that internal pressure is the most important factor that affecting the pipeline buckling pattern. Buckling mode of non-pressure pipeline is collapse under reverse fault. Wrinkles appear on buried pressure pipeline when the internal pressure is more than $0.4 P_{\max }$. Four buckling locations appear on the buried pressure pipeline under bigger fault displacement. There is only one wrinkle on the three locations of the pipeline in the rising formation, but more wrinkles on the fourth location. Number of the wrinkle ridges and length of the wavy buckling increase with the increasing of friction coefficient. Number of buckling location decreases gradually with the decreasing of diameter-thick ratio. A protective device of buried pipeline was designed for preventing pipeline damage crossing fault area for its simple structure and convenient installation. Those results can be used to safety evaluation, maintenance and protection of buried pipelines crossing fault area.

\section{Introduction}

Fault movement is one of the threats for the structural integrity of buried pipelines caused by earthquakes (Vazouras et al., 2010). Evaluation of the response of buried oil-gas pipelines crossing the faults is among their top seismic design priorities (Karamitros et al., 2007). This is because the axial and bending strains induced to the pipeline by fault may become fairly large and lead to rupture, either due to tension or due to buckling. Leakage of oil-gas pipelines may be results in explosion, poisoning, fire and other accidents. That will lead to huge losses of life and property, or cause social instability. Plastic deformation of buried steel pipeline will reduce the carrying capacity and service life, and pose a potential risk. Generally, there are three types for the fault, they are normal fault, reverse fault and strike-slip fault. The fault motion in this case depends on both the fault dip angle $\phi$ and the pipeline crossing angle $\beta$, which are present in the horizontal and the vertical plane respectively (Shantanu et al., 2011). Mechanical behaviors of the buried steel pipeline under different types of faults are different for the different stratum movement mechanisms.

There are several ways to address the problem. Modern numerical techniques based on finite element method allow a detailed analysis to be performed (Oleg and Vladimir, 2010). The behavior of buried steel pipelines subjected to excessive ground deformation has received significant attention in the pipeline community in the recent year (Vazouras et al., 2012). Wang et al. (2011) analyzed the strain of buried pipes under strike-slip faults. Duan et al. (2011) presented a design method of subsea pipelines against earthquake fault movement, but not considering the buckling morphology of the subsea pipeline cross section. Vazouras et al. $(2010,2012)$ studied the mechanical behavior of buried pipelines crossing active strike-slip faults. Liu et al. (2008) presented a shell finite element simulation and reported axial strain predictions along the non-pressure pipeline. In fact, buckling modes of non-pressure pipeline and pressure pipeline are different under fault displacement. Due to hanging wall moving towards the foot wall during reverse fault movement, one can expect a 
significant amount of axial shortening in the pipeline. Compressive stress may cause buckling of the buried pipeline either in the beam mode or in the shell mode (Shantanu et al., 2011). Some theory analysis methods are established on beam model and rope model, buckling modes of the pipeline cross section cannot be obtained (Liu, 2002). Pipeline is a thin shell structure, when the large deformation appears on the cross section of pipeline, superposition principle cannot be used for the interaction of axial strain and bending strain. And there may be residual stress and stress concentration for the pipeline. The simplified method established by Vazouras considering the S-shape deformed pipeline is only based on geometric deformation of the pipeline, the pipeline-soil was not considered. The bending deformation of the buried pipeline is a non-smooth curve after collapse or wrinkle appears (see farther below). Thus, many simplified methods earlier prove to be inadequate for buckling analysis of pipeline crossing reverse fault, and the finite element method is more suitable.

In this paper, the buckling behaviors of the buried nonpressure and pressure pipeline under reverse fault displacement were investigated by finite element method, considering the soil-pipeline interaction. Effects of buried depth, internal pressure, diameter-thick ratio, fault displacement and friction coefficient on deformation, buckling mode and strain of buried steel pipeline were discussed. And a protective device of buried pipeline was designed for preventing pipeline damage. The results can be used to safety evaluation, maintenance and protection of buried pipelines crossing fault area.

\section{Finite element model}

The structural response of steel pipeline under reverse fault is examined numerically, using the general purpose finite element program ABAQUS. The nonlinear material behavior of the steel pipeline and the surrounding soil, the interaction between the soil and buried pipeline, as well as the distortion of the pipeline cross-section and the deformation of the surrounding soil are modeled in a rigorous manner, so that the pipeline performance criteria are evaluated with a high-level of accuracy. The pipeline is embedded in an elongated soil prism along the $x$ axis shown in Fig. 1a. Figure $1 \mathrm{~b}$ shows the buried pipeline mesh and Fig. 1c depicts the mesh of the soil in $y z$ plane. Four-node reduced-integration shell elements (S4R) are employed for modeling the cylindrical pipeline segment, and eight-node reduced-integration elements (C3D8R) are used to simulate the surrounding soil. The fault dip angle $\phi=45^{\circ}$, and the pipeline crossing angle $\beta=0^{\circ}$.

The fault plane divides the soil in two blocks of equal size (Fig. 1a). The fault hanging wall moves for the reverse fault, and the fault footwall is not moving. The analysis is conducted in two steps as follows, gravity loading is applied firstly, then reverse fault displacement is imposed. The

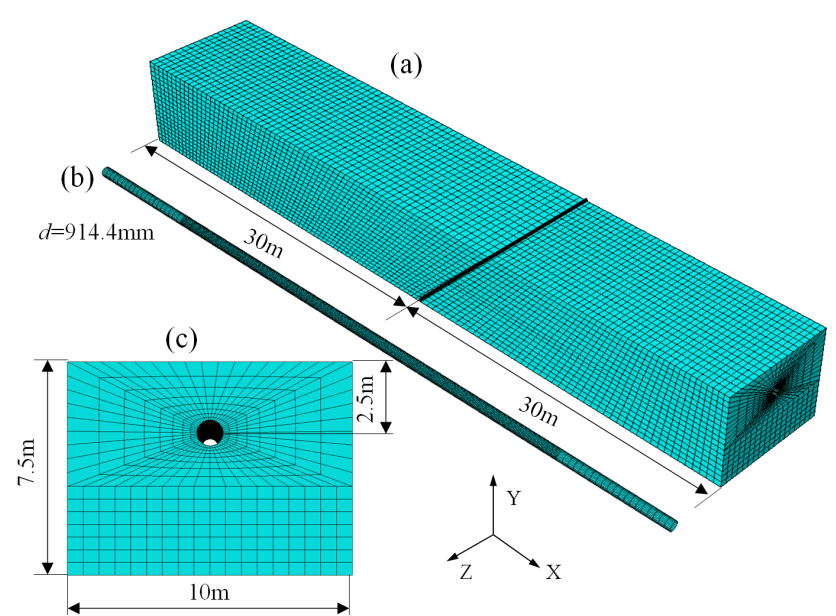

Figure 1. Finite element model. (a) The whole model, (b) the buried pipeline and (c) cross section of the model.

nodes on the bottom boundary plane of the fault footwall (soil nodes) remain fixed in the $y$ directions. The end nodes of the fault footwall remain fixed in the horizontal direction (including the end nodes of the steel pipeline). A uniform oblique displacement due to reverse fault is imposed at the bottom nodes of the fault hanging wall. For the case of pressurized pipelines, an intermediate step of internal pressure application is considered (after the application of gravity and before the fault displacement is activated). The interface between the outer surface of the pipeline and the surrounding soil is simulated with a contact algorithm, which allows separation of the pipeline and soil, and accounts for interface friction. The discretization method of surface to surface used in contact pair can get more accurate contact stress, and reduce the penetration behavior between surfaces. Isotropic coulomb friction is applied through an appropriate friction coefficient $\mu$. In the majority of results reported in the study, $\mu$ is considered equal to 0.3 .

Numerical results are obtained for X65 steel pipelines. The pipeline diameter $d$ is $0.9144 \mathrm{~m}$ ( $36 \mathrm{in}$ ), which is a typical size for oil and gas transmission pipeline. The pipeline wall thickness $t$ is considered equal to $8 \mathrm{~mm}$. The pipeline-soil model has dimensions $60 \mathrm{~m} \times 7.5 \mathrm{~m} \times 10 \mathrm{~m}$ in directions $x$, $y, z$, respectively. Taking loess for example, it has a cohesion $c=24.6 \mathrm{kPa}$, friction angle $\varphi=11.7^{\circ}$ (Wang et al., 2010), Young's modulus $E=33 \mathrm{MPa}$, Poisson's ratio $v=0.44$, density $\rho=1400 \mathrm{~kg} \mathrm{~m}^{-3}$. The X65 steel material are typical steel materials for oil and gas pipeline applications, with a nominal stress-strain curve shown in Fig. 2 (Vazouras et al., 2010). The yield stress $\sigma_{\mathrm{y}}$ of X65 is $448.5 \mathrm{MPa}$. Young's modulus of steel material equal to $210 \mathrm{Gpa}$, Poisson's ratio is 0.3 , density is $7800 \mathrm{~kg} \mathrm{~m}^{-3}$. Considering a safety factor equal to 0.72, as suggested in American Socienty of Mechanical Engineers (2007), and the maximum operating pressure $P_{\max }$ of this pipeline given by $P_{\max }=0.72 \times\left(2 \sigma_{\mathrm{y}} t / \mathrm{d}\right)$. 


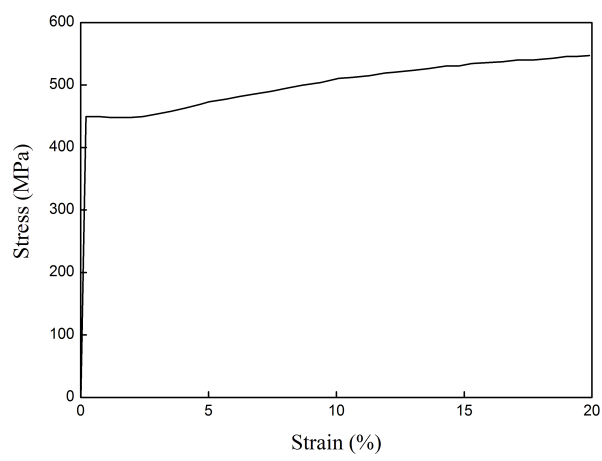

Figure 2. The stress-strain curve of X65.

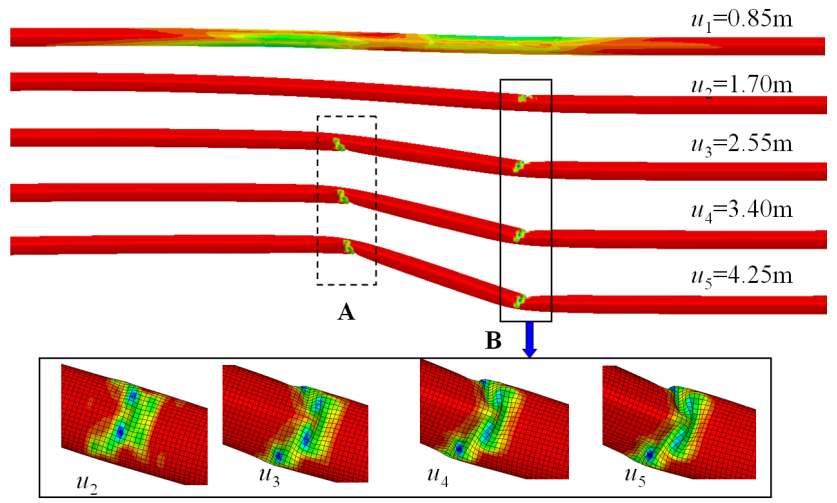

Figure 3. Buckling behaviors of the non-pressure pipeline under different reverse fault displacements.

\section{Results and discussions}

\subsection{Buckling of non-pressure pipeline}

When the buried depth $h=2.5 \mathrm{~m}$, buckling of the buried nonpressure pipeline under different reverse fault displacements is shown in Fig. 3. Under a small reverse fault displacement, there are two plastic areas on either side of the fault plane. Buckling appears on the section B of the pipeline with the increasing of fault displacement firstly. The buckling mode of non-pressure pipeline is collapse. Then buckling occurs on section A with the fault displacement increases. Buckling modes of the two locations are the same. Deformation shape of the pipeline becomes from S-shape to Z-shape after collapse appears. Local collapse is more serious with the fault displacement.

Figure 4 shows the deformations of buried non-pressure pipeline and surrounding soil when the reverse fault displacement is $3.2 \mathrm{~m}$. A part of the model corresponding to the symmetrical vertical section in the longitudinal direction is shown. Deformations of the two blocks result from the contact interaction with the buried pipeline. Soil arches appear on the top surfaces on both sides of the fault plane. These deformations are caused by the pipeline-soil interaction in the process of the pipeline movement within the surround-

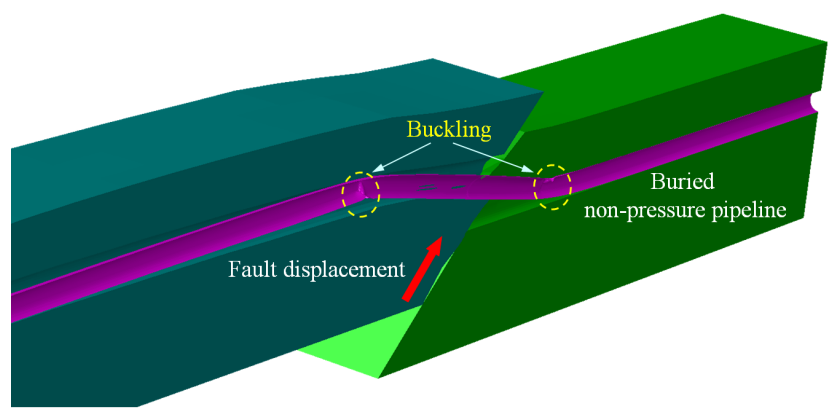

Figure 4. Deformations of the buried non-pressure pipeline and surrounding soil.

ing soil. The pipeline is not contact with the hole wall at all. At the two buckling locations, the upper parts of the pipeline contact with the hole wall, while gaps between the pipeline and the surrounding soil under large fault displacement. So, the friction between the soil and buried pipeline is difficult to solve by theoretical analysis method.

\subsection{Buckling of pressure pipeline}

When the buried depth $h=2.5 \mathrm{~m}$, pipeline pressure $P=P_{\max }$, buckling of the buried pressure pipeline under different reverse fault displacements is shown in Fig. 5. There are four parts of the buried pipeline with local buckling under reverse fault displacement. When the fault displacement is small, plastic strain appears but with no buckling deformation. With the increasing of the fault displacement, the buckling of section A and D appears firstly, then it appears on section $\mathrm{B}$, and appears on section $\mathrm{C}$ lastly. There is only one wrinkle on the section $\mathrm{A}, \mathrm{B}$ and $\mathrm{C}$, but more wrinkles on section D.

The bending moment increases with the increasing of the fault displacement. For pipeline buckling of section D (Fig. 5a), strain of the lower part is tension strain, while it is mainly compression strain in the upper part. Wrinkle amplitudes increase with the increasing of the fault displacement. For the pipeline buckling of section A, B and C (Fig. 5b), with the increasing of the reverse fault displacement, wrinkle amplitude of section A decreases, wrinkle amplitude of section $\mathrm{B}$ increases first and then decreases, while it increases in section C. Because the appear of the wrinkles in section B and $\mathrm{C}$ can absorb the energy released by section $\mathrm{A}$. The wrinkle amplitude that far from the fault plane can be eased by the new wrinkle near the fault plane. Wrinkles may reduce the strength of the pipeline and increase the difficulty of pigging. If the plastic strain is bigger than the rupture strain, the leakage will occur.

Variations of axial strain along the two outer generators of the pipeline section D are shown in Fig. 6. At the compression side (Fig. 6a), the outset of local buckling is considered at the stage where outward displacement of the pipeline wall starts at the area of maximum compression. At that stage, 


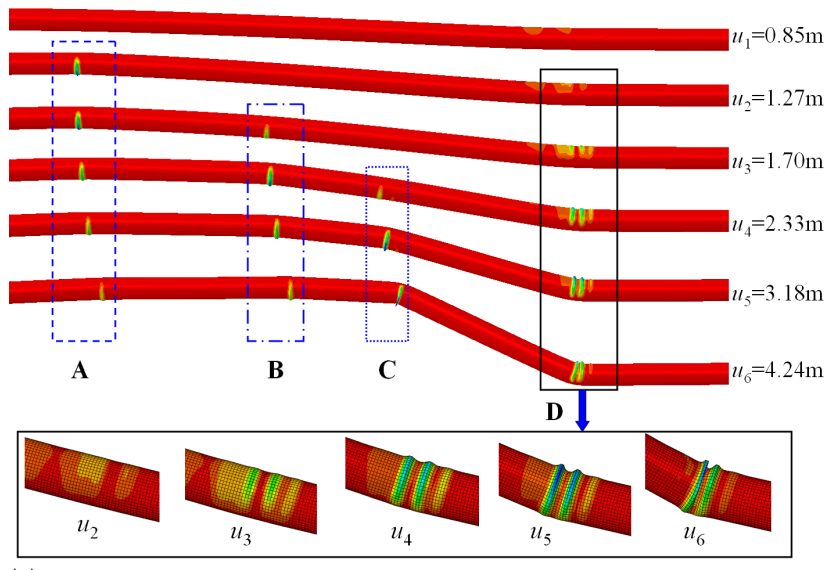

(a)

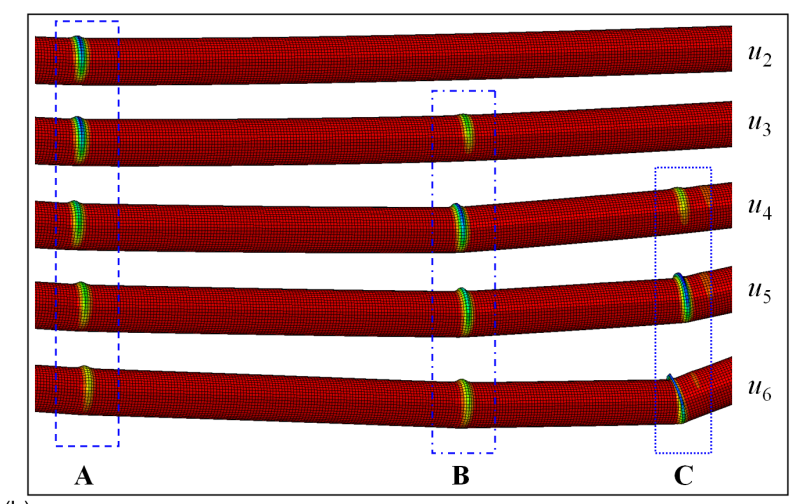

(b)

Figure 5. Buckling behaviors of the buried pressure pipeline under different reverse fault displacements. (a) Buckling of the pipeline and (b) local amplification figure.

bending strains due to pipeline wall wrinkle development, associated with significant tensile strains at the "ridge" of the buckling. So that the longitudinal compressive strains at this location at the outer surface start decreasing, forming a short wave at this location (Vazouras et al., 2010). At the ridge of the wave, axial strain is the negative maximum value. While at the valley, axial strain is the positive maximum value. The wave amplitude increases with the increasing of the reverse fault displacement. At the tension side (Fig. 6b), the axial strain increases with the increasing of the reverse fault displacement, and the strain curve becomes M-shape under large fault displacement.

Figure 7 shows the bending deformation of the buried pressure pipeline under different fault displacements. Bending deformation of the buried pipeline under bending moment caused by non-uniform deformation of the surrounding soil under reverse fault displacement. With the increasing of fault displacement, bending deformation curve is more serious. Meanwhile, the deformation shape becomes from a smooth curve to a non-smooth curve after the inflection point appears. The inflection points reflect the local buck-
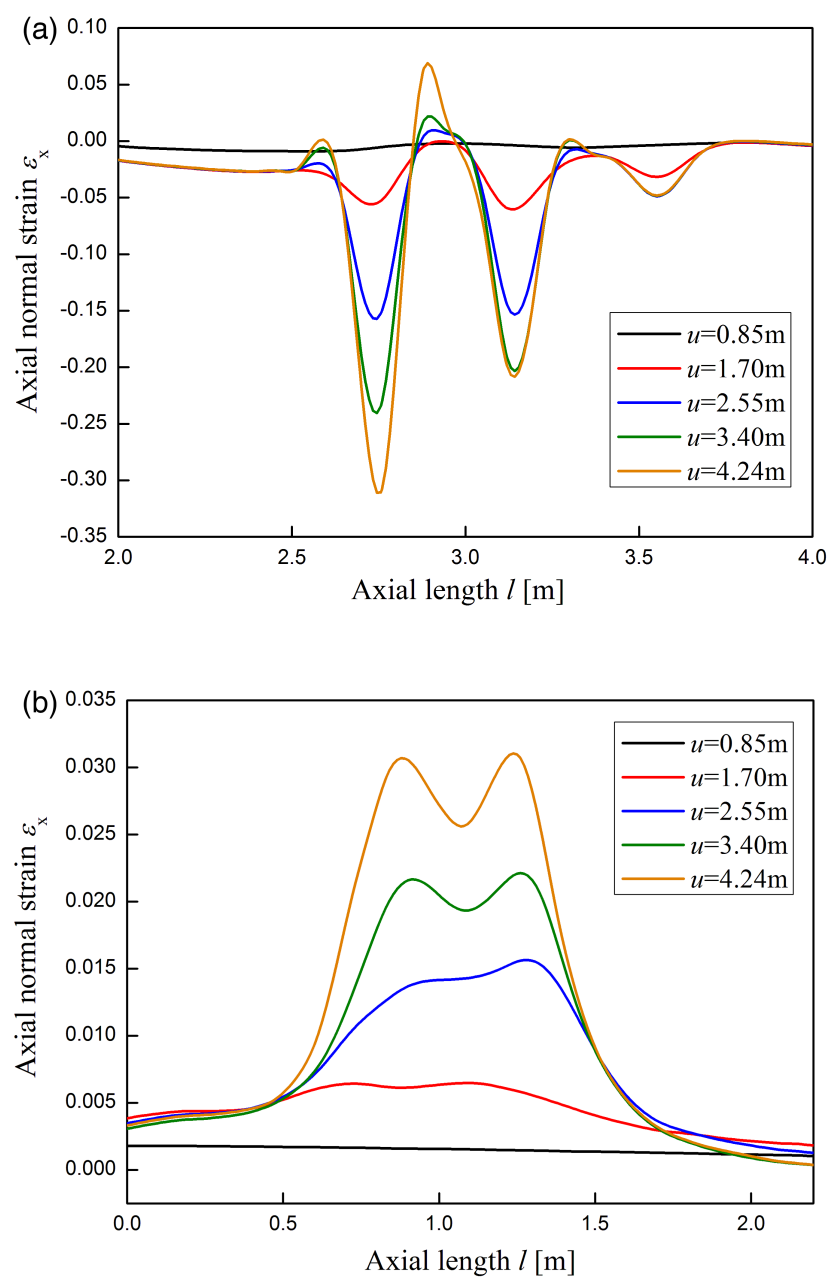

Figure 6. Variation of axial strain of the buckling area on section D under different reverse fault displacements. (a) Axial strain at the compression side and (b) axial strain at the tension side.

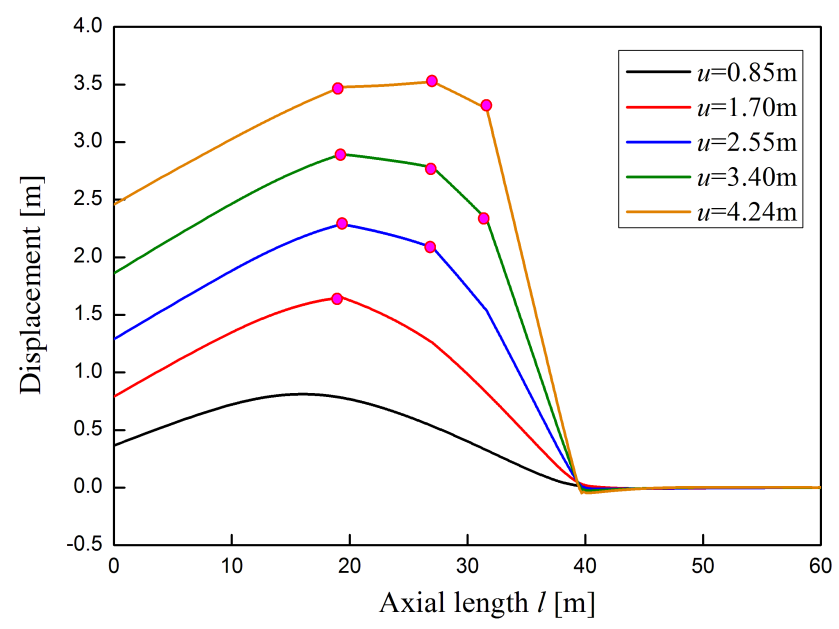

Figure 7. Bending deformations of the buried pipeline under different fault displacements. 


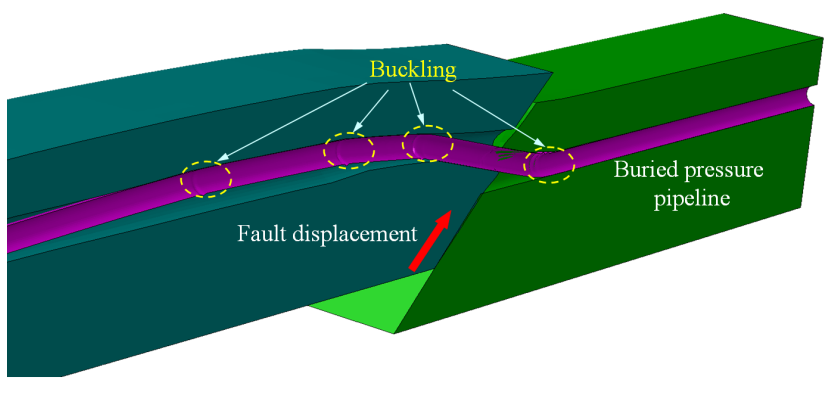

Figure 8. Deformations of the buried pressure pipeline and surrounding soil.

lings. There are three inflection points of the deformation curve in the moving block.

Figure 8 shows the deformations of the pressure pipeline and surrounding soil when the fault displacement is $3.2 \mathrm{~m}$. The pipeline sections near the fault plane contact with the upper and lower part of the hole wall respectively. Deformations of the two block soils are different. Because the top surfaces of the soil can be arched by the bending deformed pipeline, but deformation of the lower part soil is small for the thick stratum.

\subsection{Effect of pipeline pressure}

When the buried depth $h=2.5 \mathrm{~m}$, reverse fault displacement $u=3.4 \mathrm{~m}$, friction coefficient $f=0.3$, buckling behavior of the buried pressure pipeline under different pipeline internal pressures is shown in Fig. 9. When the internal pressure $P \leq 0.4 P_{\max }$, there are only two buckling locations in the pipeline. When $P=0.5 P_{\max }$, there are three buckling locations. When $P \geq 0.5 P_{\max }$, four buckling locations are on the pipeline. Buckling morphologies of section $\mathrm{D}$ pipeline are different under different internal pressures. Collapse buckling appears when the internal pressure is zone or small. While wrinkle appears when the internal pressure is more than $0.4 P_{\max }$. The internal pressure can enhance the stiffness of the buried pipeline to resistance to bending moment.

Variations of axial strain at the compression side of the pipeline in section $\mathrm{D}$ under different internal pressures are shown in Fig. 10. At the compression side, when $P \leq 0.4 P_{\max }$, there is only one crest and valley, the tensile strain is big and the compression strain is small. It illustrates that the buckling pattern is collapse. But with the increasing of the internal pressure, the tensile strain decreases and the compression strain increases, and more than two valleys appear. When $P=P_{\max }$, there are three valleys in section D. It illustrates that the buckling pattern become to wavy pattern. Therefore, the internal pressure is the most important factor that affecting the pipeline buckling pattern.

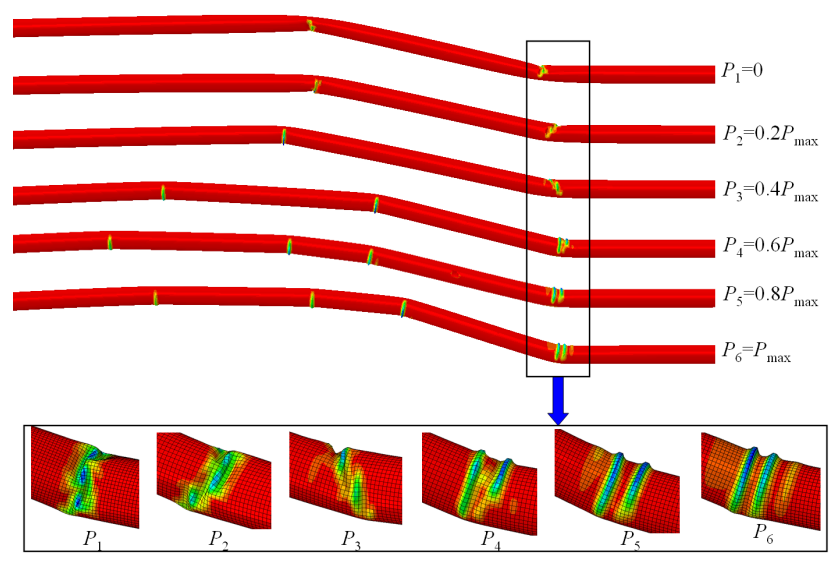

Figure 9. Buckling behaviors of the buried pipeline under different internal pressures.

\subsection{Effect of diameter-thick ratio}

When the buried depth $h=2.5 \mathrm{~m}$, reverse fault displacement $u=3.4 \mathrm{~m}$, friction coefficient $f=0.3$, buckling behavior of the buried pressure pipeline under different diameterthick ratios is shown in Fig. 11. With the decreasing of the diameter-thick ratio, the buckling locations decrease gradually. The greater diameter-thick ratio can enhance the ability to resistance to bending moment. When $d / t=45$, there is only one buckling location, and the bending curve of the pipeline is smooth. The amplitude of the wrinkle decreases with the decreasing of the diameter-thick ratio. Therefore, ability to resist damage by reverse fault displacement can be improved by increasing the wall thickness in a dangerous hazard area.

Variations of axial strain at the compression side of the pipeline in section D under different diameter-thick ratios are shown in Fig. 12. At the compression side, with the decreasing of the diameter-thick ratio, wave of the strain curve becomes smooth gradually, but the number of the wave crest increases. The maximum tensile strain and compressive strain decrease with the decreasing of the diameter-thick ratio. When $d / t=45$, compressive strains of the three valleys are close to each other. It illustrates that the probability of pipeline buckling is smaller with a lower diameter-thick ratio.

\subsection{Effect of friction coefficient}

In the process of reverse fault displacement, the friction force between surrounding soil and pipeline can be divided into two parts. One is static friction force before the soil yield, the other is the sliding friction force after the soil yield (Liu, 2002). When the axial deformation of the pipeline appears, the surrounding soil will be resistance to the relative movement. When the resistance reaches limit value, the surround- 

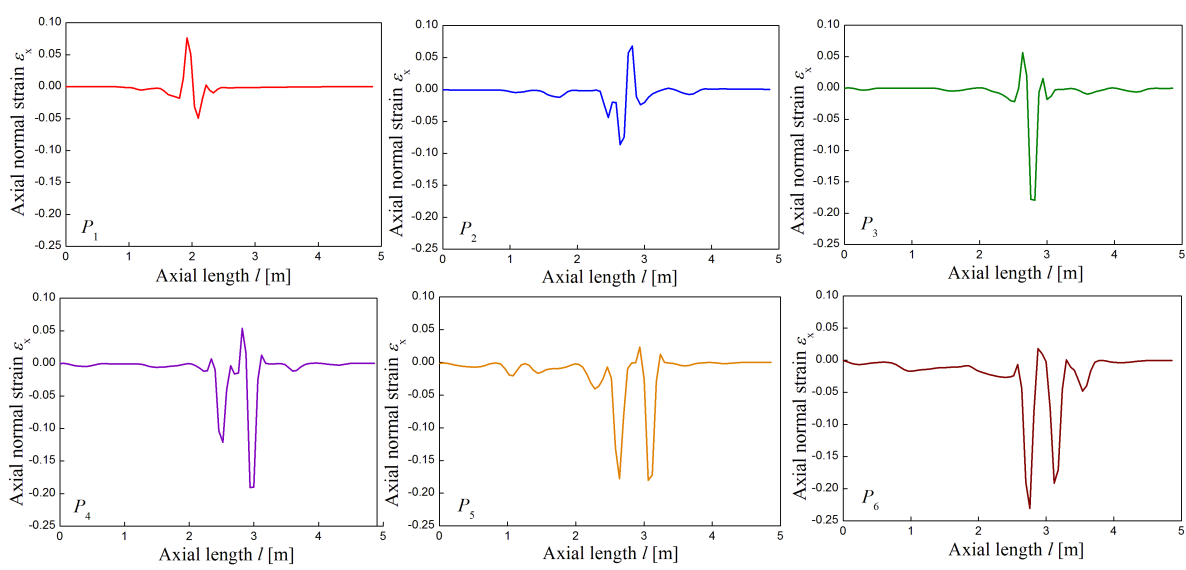

Figure 10. Variations of axial strain at the compression side of the buckling area in section D under different internal pressures.

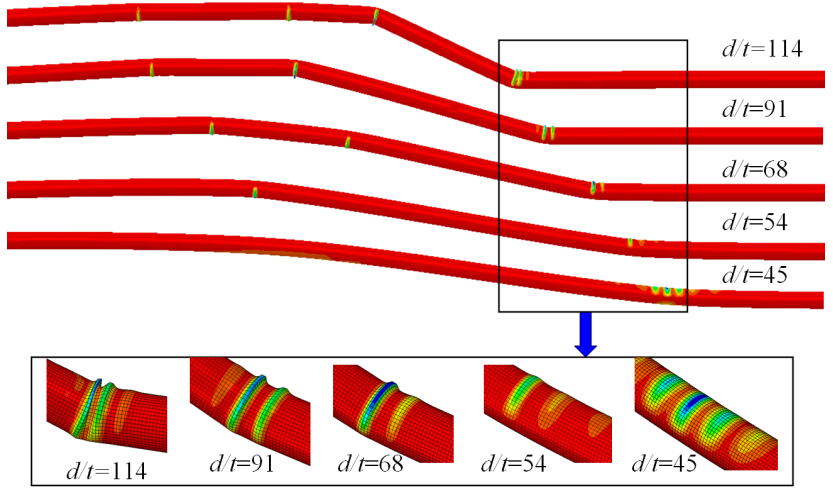

Figure 11. Buckling behaviors of the buried pipeline under different diameter-thick ratios.

ing soil will yield, then relative sliding appears between the pipeline and soil.

When the buried depth $h=2.5 \mathrm{~m}$, reverse fault displacement $u=4.2 \mathrm{~m}$, diameter-thick ratio $d / t=114$, variations of axial strain at the compression side of the pipeline in section D under different friction coefficients are shown in Fig. 13. At the compression side, the number of the wrinkle ridges increases with the increasing of friction coefficient. The length of the wavy buckling also increases in section D. When friction coefficient $f<0.4$, the curve shapes are similar. With the increasing of the friction coefficient, the valley number and the maximum compressive strain increase.

\subsection{Effect of buried depth}

When the reverse fault displacement $u=2.4 \mathrm{~m}$, diameterthick ratio $d / t=114$, friction coefficient $f=0.3$, variations of axial strain at the compression side of the pipeline in section D under different buried depths are shown in Fig. 14. At the compression side, the maximum axial tensile strain decreases with the increasing of the buried depth. When the buried depth $h \geq 2.5 \mathrm{~m}$, the compression strain of the first ridge is the biggest.

\section{Protective device design}

In order to reduce the failure probability and improve the service life of buried pipeline under reverse fault, protective measures should be designed. In this paper, a protective device of the buried pipeline is designed for preventing pipeline damage crossing fault area. As shown in Fig. 15, it consists of buried pipeline, protective pipeline, sealing ring, baffle ring, flange structure, end cone pipeline, water channel and water. For the reverse fault area, protective pipeline is sleeved on the buried pipeline. Flange structures are used to connect the protective pipeline and end cone pipelines. Cone pipelines were installed in the end. Sealing rings are installed between the buried pipeline and protective pipeline for sealing the fluid. Baffle rings are installed in front of the sealing rings. Water can be pumped into the annular space between the buried pipeline and protective pipeline by the water channel.

Under reverse fault displacement, deformation appears on protective pipeline firstly, and annulus hindered the contact between protective pipeline and buried pipeline. If the protection pipeline is compressed under reverse fault displacement, pressure of the water between the buried pipeline and protective pipeline can act on the buried pipeline. It can avoid the local deformation of buried pipeline caused by large local loads. If buckling appears on protective pipeline, it can be timely repaired and replaced without stopping the transmission of oil and gas. So, this protective device can effectively protect the oil and gas pipeline. And the protective device can be widely used in different locations for its simple structure and convenient installation. However, the reverse fault plane is difficult to be predicted in advance. So, length of the protective device may be longer to reduce the effect of reverse fault. 


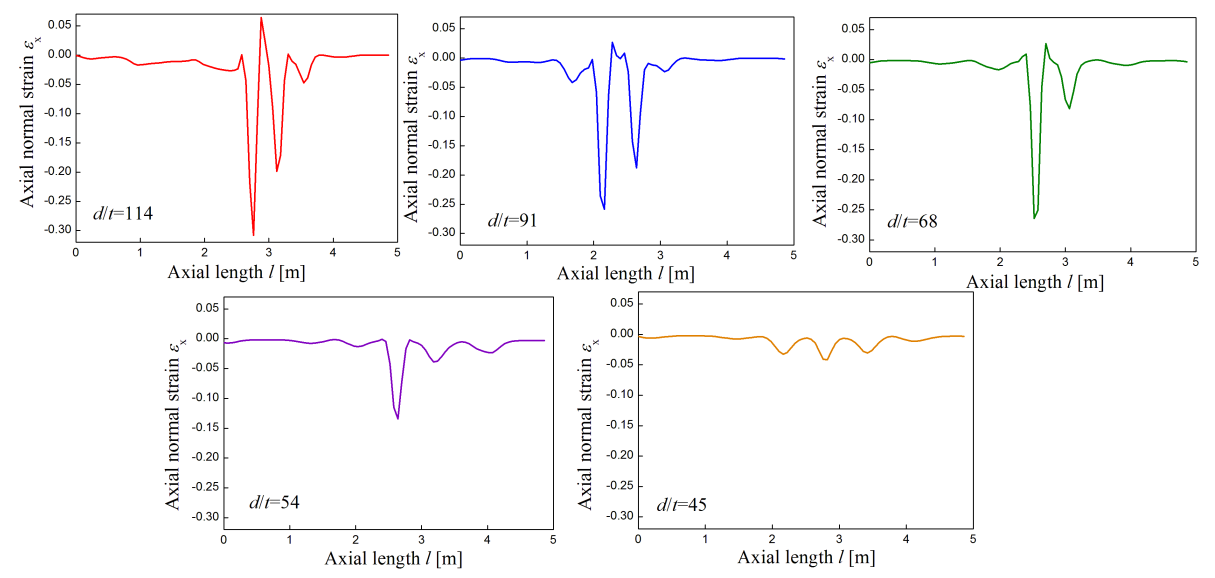

Figure 12. Variations of axial strain at the compression side of the buckling area under different diameter-thick ratios.
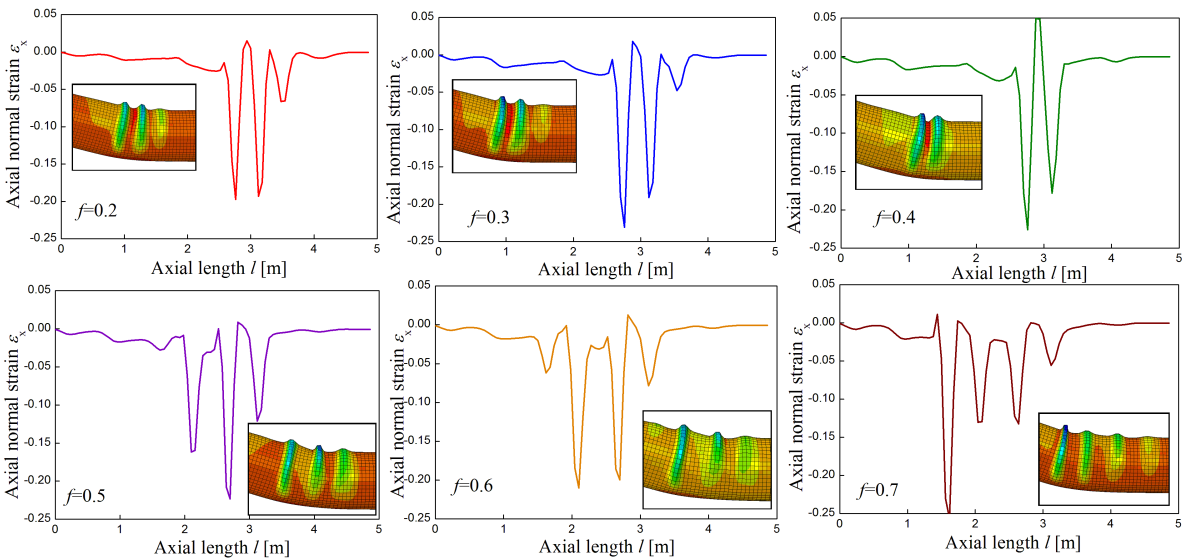

Figure 13. Variations of axial strain at the compression side of the buckling area under different friction coefficients.
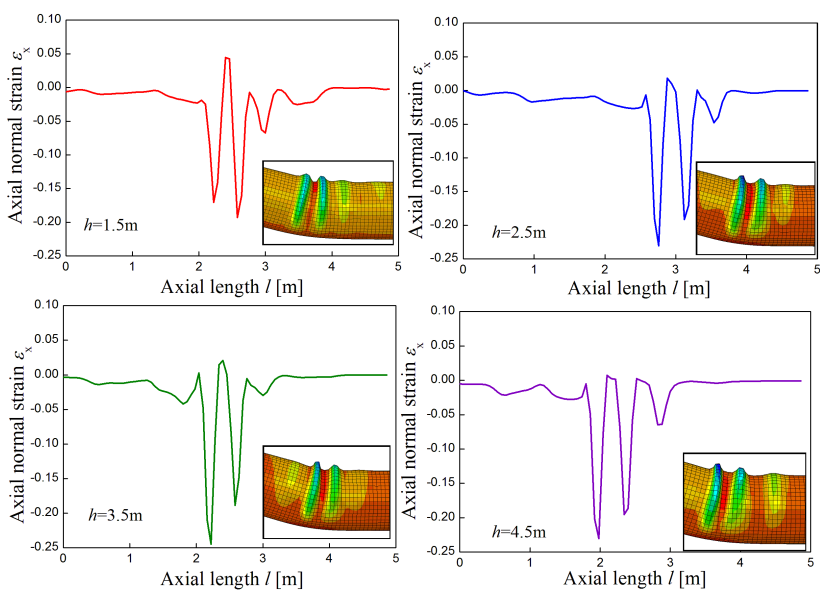

Figure 14. Variations of axial strain at the compression side of the buckling area under different buried depths.

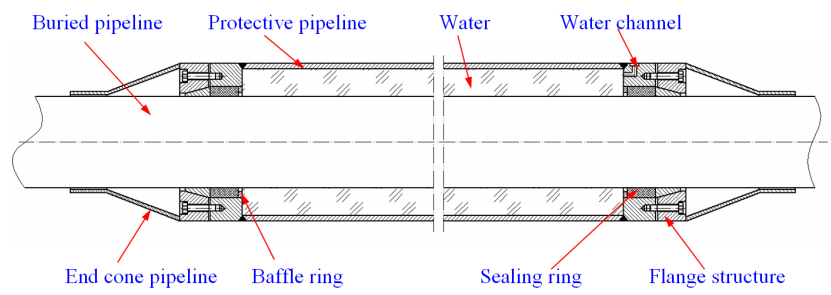

Figure 15. A protective device of the buried pipeline crossing reverse fault area.

Figure 16 shows the buckling behaviors of the pressure pipeline in two conditions when the fault displacement is $1.9 \mathrm{~m}$. In this case, the buried pipeline diameter is $660 \mathrm{~mm}$, the protective pipeline diameter is $762 \mathrm{~mm}$, the annular pressure is $0.3 \mathrm{MPa}$. Two buckling locations appear on the buried pipeline when there is no protective device. The maximum plastic strain is 0.1418 . Under protective device, there is only one plastic zone, and the maximum plastic strain is 0.0053 . 


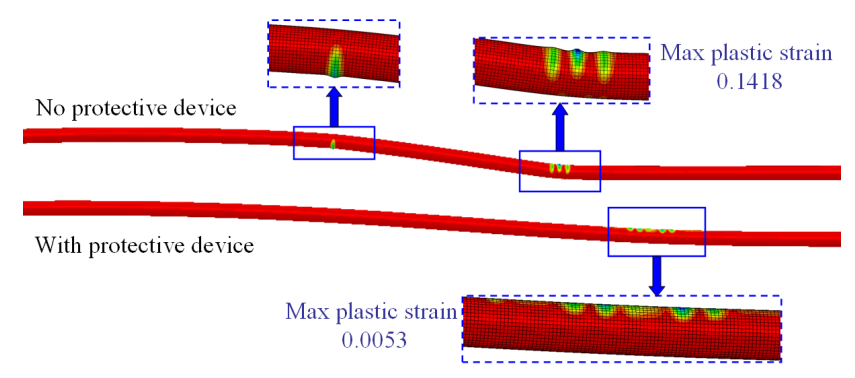

Figure 16. Buckling behaviors of the buried pressure pipeline in two conditions.

Therefore, the protective device can effectively protect the buried pipeline crossing reverse fault area.

\section{Conclusions}

Numerical simulation of buckling behavior of the buried X65 pipeline under reverse fault displacement in this paper led to the follow conclusions:

1. The buckling mode of non-pressure pipeline is collapse under reverse fault displacement. But wrinkles appear on buried pressure pipeline when the internal pressure is more than $0.4 P_{\max }$. For pressure pipeline, there are four buckling locations on the buried pipeline under reverse fault displacement. There is only one wrinkle on the three locations of the pipeline in the rising formation, but more wrinkles on the fourth location. Axial strain of the wrinkles section increases with the increasing of the reverse fault displacement. Internal pressure is the most important factor that affecting the pipeline buckling pattern.

2. With the decreasing of the diameter-thick ratio, the buckling locations decrease gradually. Strain curve becomes smooth gradually with the decreasing of the diameter-thick ratio at the compression side. Thick wall pipelines can be laid in the fault areas. Number of the wrinkle ridges and length of the wavy buckling increase with the increasing of the friction coefficient. Buried depth has a great effect on the buckling pattern.

3. A protective device of the buried pipeline is designed for preventing pipeline damage crossing fault area for its simple structure and convenient installation. The protective pipeline and water in the annular space can effectively protect the oil and gas pipeline under stratum deformation.

4. The methodology of deformation evaluation, buckling mode and limit state analysis developed in the paper can be used to safety assessment and prediction of buried pipeline crossing fault area. But a comparison to experimental results or real event data is needed for the verification of the finite element model. The protective device of the buried pipeline is also needed to be tested by experiments, and its performance needs to be evaluated.

Author contributions. J. Zhang completed the numerical simulation of the results and preparation of the manuscript. Z. Liang contributed to the initial design scheme, with assistance from all co-authors. C. J. Han and H. Zhang provided many contributions to the preparation of the manuscript.

Acknowledgements. This research work was supported by the Science and Technology Innovation Talent Engineering Project of Sichuan Province (2015097) and National Natural Science Foundation of China (51474180).

Edited by: A. Barari

Reviewed by: N. Achour and two anonymous referees

\section{References}

American Society of Mechanical Engineers: Gas transmission and distribution piping systems, ANSI/ASME B31.8, New York, 2007.

Duan, M. L., Mao, D. F., Yue, Z. Y., Segen, E., and Li, Z. G.: A seismic design method for subsea pipelines against earthquake fault movement, China Ocean Eng., 25, 179-188, 2011.

Karamitros, D. K., Bouckovalas, G. D., and Kouretzis, G. P.: Stress analysis of buried steel pipelines at strike-slip fault crossings, Soil Dyn. Earthq. Eng., 27, 200-211, 2007.

Liu, A. W.: Response analysis of a buried pipeline crossing the fault based on shell-model, China Seismological Bureau, Institute of Geophysics, Beijing, 2002.

Liu, M., Wang, Y. Y., and Yu, Z.: Response of pipelines under fault crossing, Proceedings of the international offshore and polar engineering conference, Vancouver, BC, Canada, 162-166, 2008.

Oleg, V. T. and Vladimir, P. C.: A semi-analytical approach to a nonlinear stress-strain analysis of buried steel pipelines crossing active faults, Soil Dyn. Earthq. Eng., 30, 1298-1308, 2010.

Shantanu, J., Amit, P., and Arghya, D.: Analysis of buried pipelines subjected to reverse fault motion, Soil Dyn. Earthq. Eng., 31, 930-940, 2011.

Vazouras, P., Karamanos, S. A., and Dakoulas, P.: Finite element analysis of buried steel pipelines under strike-slip fault displacement, Soil Dyn. Earthq. Eng., 30, 1361-1376, 2010.

Vazouras, P., Karamanos, S. A., and Dakoulas, P.: Mechanical behavior of buried steel pipes crossing active strike-slip faults, Soil Dyn. Earthq. Eng., 41, 164-180, 2012.

Wang, B., Li, X., and Zhou, J.: Strain analysis of buried steel pipelines across strike-slip faults, J. Cent. S. Univ. Technol., 18, 1654-1661, 2011.

Wang, S. F., Yin, Y. P., and Men, Y. M.: In-situ test and numerical analysis of skid resistance for micropile to loess landslide, Hydrogeol. Eng. Geol., 37, 22-26, 2010. 